\title{
The menace of caesarean scar pregnancy: a management challenge in modern obstetrics
}

\author{
Anjali Choudhary*, Meenakshi Tanwar, Shweta Nimonkar, Shailly Singh
}

Department of Obstetrics and Gynaecology, Shri Guru Ram Rai Institute of Medical and Health Sciences, Patel Nagar, Dehradun, Uttarakhand, India

Received: 12 July 2020

Revised: 17 August 2020

Accepted: 20 August 2020

*Correspondence:

Dr. Anjali Choudhary,

E-mail: mcgsunil@gmail.com

Copyright: (c) the author(s), publisher and licensee Medip Academy. This is an open-access article distributed under the terms of the Creative Commons Attribution Non-Commercial License, which permits unrestricted non-commercial use, distribution, and reproduction in any medium, provided the original work is properly cited.

\section{ABSTRACT}

Background: With the increasing caesarean section rates a new challenging evil of caesarean scar pregnancy (CSPs) has emerged. As a variant of ectopic pregnancy caesarean scar pregnancy is the rarest of all. Diagnosis and management of CSP can be challenging especially when there are no early symptoms and even lessor index of suspicion. Objective of this endeavour was to present one institute experience of management of caesarean scar pregnancies.

Methods: This are a retrospective analysis of women admitted with CSP. Detailed history, investigation, management protocols and complications were noted.

Results: Of the total cases maximum women $(60 \%)$ had history of previous two caesarean section. $90 \%$ of cases were managed successfully with intra-sac or systemic methotrexate, and surgical evacuation with Foley's catheter tamponade, only two women needed hysterectomy for uncontrolled bleeding.

Conclusions: Caesarean scar pregnancy is a diagnostic and management challenge in modern obstetrics. Early ultrasound diagnosis helps in planning a successful medical treatment and serves to preserve uterus and fertility. Treatment with transabdominal intra-sac methotrexate and Foley's catheter for tamponade is safe and effective method of treating CSPs.

Keywords: Caesarean scar pregnancy, Conservative management, Massive haemorrhage, Morbid placental adhesions

\section{INTRODUCTION}

With the increasing caesarean section rates, a new challenging evil of caesarean scar pregnancy has emerged. As a variant of ectopic pregnancy caesarean scar pregnancy is the rarest of all. Implantation and growth of a conceptus in the niche of a previous caesarean scar often leads to morbid attachment of placenta to uterine myometrium, a condition famously known as placenta accreta syndrome (PAS) consisting of placenta accreta, increta and percreta depending upon the depth of invasion into the myometrium, and caesarean scar pregnancy is an infancy of morbidly adherent placenta. Both conditions, adherent placenta and scar pregnancy are associated with significant maternal morbidity and mortality as a result of torrential obstetric haemorrhage, need for hysterectomy and massive blood transfusion, disseminated intravascular coagulation (DIC), renal failure and injury to adjacent organs.

Caesarean scar pregnancy (CSP) was first reported in 1078 by Larsen and Solomon when during dilatation and evacuation of a six-week pregnancy with incomplete abortion, led to profuse life-threatening haemorrhage necessitating a laparotomy and a pregnancy embedded in the caesarean scar was detected. ${ }^{1}$ The bleeding was due to erosion of a major vessel in the scar. Since then up to 2002 only 19 cases were reported, thereon the incidence of scar pregnancy is rising proportionate to the rise in section rates. ${ }^{2}$ In the current times incidence of scar pregnancy is 
1: 800 to 1: $2200(0.05$ to $0.04 \%)$ and $6 \%$ of all ectopic pregnancies. ${ }^{3,4} \mathrm{~A}$ woman with one caesarean has a risk of $1.5 \%$ of having a pregnancy in the scar. Silver et al, $13 \%$ report the risk of adherent placenta after one caesarean, $23 \%$ after two caesareans and $29 \%$ after previous three caesarean sections. One of cause of rise in frequency can be attributed to access to modern imaging modalities like ultrasound and transvaginal ultrasound. ${ }^{4}$ Exact mechanism for the morbid adherence of placenta is not clear but defective development of decidua basalis allowing chorionic villi to penetrate the myometrium is most plausible explanation and caesarean scar pregnancy is the precursor of Morbidly adherent placenta (MAP). ${ }^{5}$ TimorTrish et al prospectively followed. Ten cases of scar pregnancy in women who opted for continuation of pregnancy and found that all ten women needed hysterectomy at the time of caesarean delivery and had histopathologic confirmation of MAP. ${ }^{6}$

Diagnosis and management of CSP can be challenging especially when there no early symptoms and even lessor index of suspicion, these pregnancies either continue to become adherent placenta syndrome or diagnosed only when come with massive bleeding after a medical or spontaneous abortion or during a suction evacuation. This raises an interesting question, should every first trimester pregnancy with a prior history of section be investigated for scar pregnancy? A diagnosis of caesarean scar pregnancy based only on symptoms and pelvic examination alone is difficult as CSP is asymptomatic in its initial phases. Later, signs of this type of pregnancy are frequently non-specific. ${ }^{4}$ Diagnosis mainly rests on ultrasonography which permits early diagnosis of scar pregnancy resulting in successful management and preventing massive haemorrhage and preserving uterus. ${ }^{7}$ Ultrasound shows presence of a gestational sac or trophoblast within the caesarean scar area and an empty uterine cavity. Other diagnostic criteria like empty cervical canal presence of yolk sac or foetal pole with or without cardiac activity in the vicinity of the scar and a positive pregnancy test. ${ }^{8}$ However, these signs are either masked or difficult to discern in cases of natural abortion or an attempted dilatation and evacuation. On Doppler examination of the CSP, there is increased vascularity. In CSP, colour Doppler imaging shows functional placental vascularization caused by increased blood flow with peak systolic velocity (PSV) greater than $20 \mathrm{~cm} / \mathrm{s}$ and pulsatalilty index (PI) lower than one. ${ }^{4,9}$ A trans-vaginal ultrasound scan, Doppler examination and magnetic resonance imaging are collectively useful in making a definite diagnosis of CSP. Calli and colleagues in a retrospective study of early pregnancy scans of women with morbidly adherent placenta, managed in third trimester, devised a novel ultrasonic sign called the 'crossover sign' depending upon the relationship between the scar, anterior uterine wall and the pregnancy sac. They used this sign to diagnose CSP and to study its progression to morbid adherent placenta. ${ }^{9}$ Early pregnancy ultrasound in women with previous sections is useful in counselling these women regarding consequences of CSP and implication of termination of pregnancy and also continuation, as both, termination or continuation of CSP can cause significant maternal morbidity.

Since many of these pregnancies lead to morbid adherence of placentae as the pregnancy continues and it has been recognised that CSP and MAP (morbid adherence of placenta) are same condition, an appropriate treatment option would be termination of pregnancy with avoidance of massive haemorrhage. The conventional dilatation and evacuations results in heavy bleeding and should be avoided according to some authors. However, a planned D/E with a Foley's balloon catheter insertion in uterine cavity for tamponade has also been tried with success. ${ }^{10,11}$ Use of systemic and local injection of methotrexate-an antimetabolite drug-with a foley's catheter is also an option for termination of CSPs. ${ }^{11}$ Wang et al reported a successful management of scar pregnancy by hysteroscopic removal. Alternatively, a surgical removal of pregnancy by laparotomy of laparoscopy or hysterectomy along with the pregnancy can be tried. Whatever the mode of treatment, the risk of heavy bleeding is always there, leading to maternal morbidity and even mortality, and management of these cases remains challenging. In this case series we present our experience in managing caesarean scar pregnancies successfully.

Objective of this study was to present our- single instituteexperiences in diagnosis and management of Caesarean scar pregnancies.

\section{METHODS}

We analyzed 24 cases of CSP diagnosed by ultrasonography (USG) retrospectively over a period of two years from March 2018 to February 2020. Study was conducted in Shri Guru Ram Rai University Medical College and Shri Mahant Indiresh Hospital, Dehradun, a tertiary referral centre. Source of data was patients' records and investigations. Pregnant women in their first trimester, with history of previous caesarean who were diagnosed or suspected of caesarean scar pregnancy were included in the study. Detailed clinical history, investigations, and management modalities were noted. These women were managed with expectant, medical treatment and/or surgical treatment. Successes, failures and complications of the treatment were analyzed. We used Microsoft excel tools for calculations.

\section{RESULTS}

There were 24 diagnosed cases of caesarean scar pregnancy during the observation period. The mean age group of the women was 32.75 years \pm 3.7 years. There were 17 third gravidas $(70.83 \%), 4$ second gravidas $(12.5 \%)$, three women fourth gravida $(12.5 \%)$ and one fifth gravida (4.1\%). Out of 24 women $12(60 \%)$ women had a history of previous two caesarean, 9 women $(37.5 \%)$ with one caesarean and one woman (5\%) with previous 3 
caesarean. Mean gestation at diagnosis was 6.7 weeks \pm 5.3 weeks. $11(55 \%)$ women presented with just amenorrhea without any symptoms, 6 women $(30 \%)$ had amenorrhea with spotting and four women $(20 \%)$ presented with heavy bleeding. Out of 20 women 16 women who received medical management the pre-treatment beta human chorionic gonadotropin (HCG) was $6577 \mu / 1$. Three women who lad pre-treatment beta HCG less than $1000 \mu / 1$ were treated expectant with serial beta HCG monitoring and all had complete resolution. Diagnosis was confirmed by ultrasonography appearance of an empty uterine cavity and the gestational sac in the scar area. Other presentation were increased vascularity, scar haematoma, and scar dehiscence. We were able to demonstrate typical signs of CSP on ultrasound in about $70 \%$ of cases, other women who presented heavy bleeding per vaginum, with attempted medical or surgical termination the USG findings were not very conclusive.

Transvaginal USG images are shown in Figure 1-4.

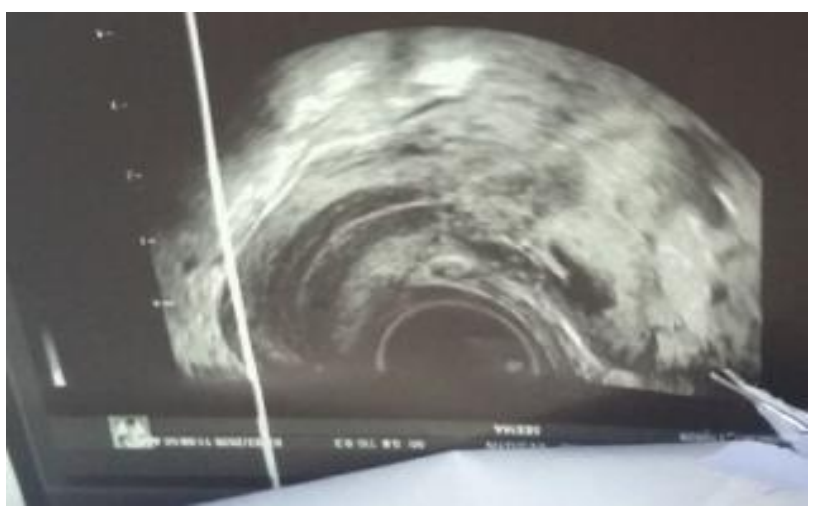

Figure 1: TVS of CSP, empty uterine cavity with G. sac at the scar site.

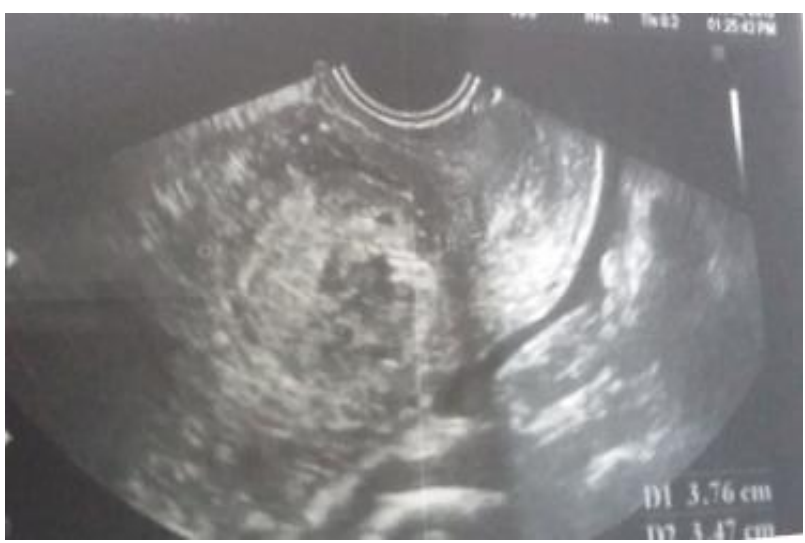

Figure 2: Heterogeneous mass at scar site suggestive of haematoma.

Eight women received systemic methotrexate out of which five cases had resolution, three women required surgical management, two women required surgical evacuation with intrauterine tamponade, and one woman needed hysterectomy for uncontrolled haemorrhage. Five women had elective termination of pregnancies with intra-sac methotrexate and Foley's balloon tamponade, all had complete resolution with no consequences on follow up.

In this study the women with elective intra-sac methotrexate with Foley's catheter in situ had the most uneventful course in hospital

There were a total of 24 cases and mean age was 32.7 years \pm 3.7 years.

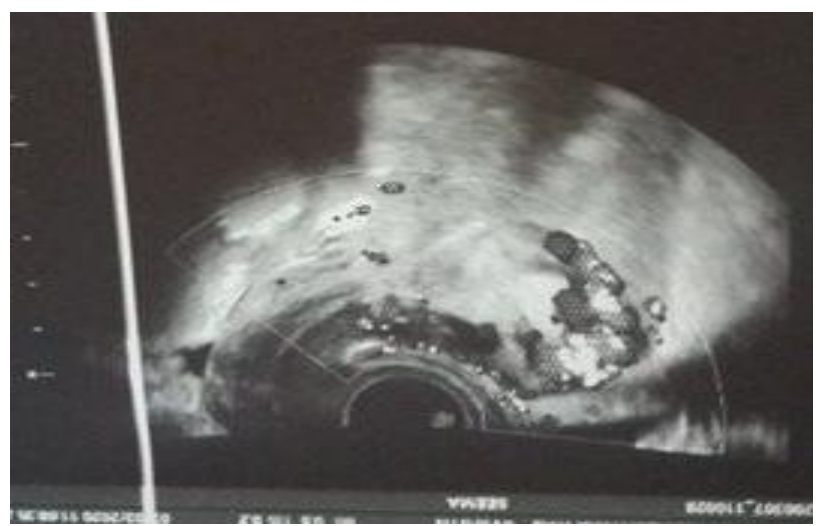

Figure 3: Heterogeneous areas with lacunae at scar site suggestive of scar dehiscence.

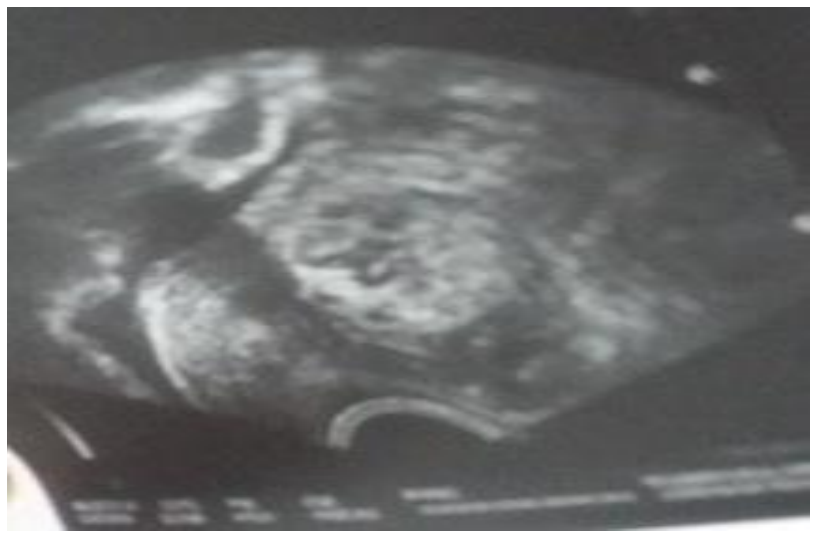

Figure 4: Collection of clots at scar site.

Table 1: Demographic details.

\begin{tabular}{|llll|}
\hline Parameter & Number & Percentage \\
\hline $\begin{array}{l}\text { Age group } \\
\text { (years) }\end{array}$ & $25-30$ & 12 & 50 \\
\hline \multirow{3}{*}{ Parity } & $31-35$ & 11 & 45.83 \\
\cline { 2 - 4 } & $>35$ & 1 & 4.16 \\
\cline { 2 - 4 } & $\mathrm{G} 2$ & 3 & 12.5 \\
\hline & $\mathrm{G} 3$ & 17 & 70.83 \\
\hline $\begin{array}{l}\text { O/H: Number } \\
\text { of previous C- } \\
\text { sections }\end{array}$ & 1 & 3 & 12.5 \\
\cline { 2 - 4 } & 2 & 1 & 4.1 \\
\hline
\end{tabular}


Table 2: Management outcome.

\begin{tabular}{|llll|}
\hline Modality of treatment & $\begin{array}{l}\text { Number }(\%) \\
\text { Expectant }\end{array}$ & $\begin{array}{l}\text { Outcome } \\
\text { Resolution }\end{array}$ & $\begin{array}{l}\text { Complications } \\
\text { None }\end{array}$ \\
\hline Systemic MTX* & $8(33.33)$ & $\begin{array}{l}\text { Resolution in 5 cases, } \\
\text { failed treatment in three } \\
\text { cases }\end{array}$ & $\begin{array}{l}\text { Two women needed surgical evacuation, one } \\
\text { woman had hysterectomy for uncontrolled } \\
\text { haemorrhage }\end{array}$ \\
\hline Local MTX (intra-sac) & $8(33.33)$ & Resolution in all cases & None \\
\hline $\begin{array}{l}\text { Surgical -D/E with } \\
\text { Foleys catheter }\end{array}$ & $4(16.66)$ & Resolution in three cases & $\begin{array}{l}\text { One required TAH* for uncontrolled } \\
\text { haemorrhage }\end{array}$ \\
\hline
\end{tabular}

*Methotrexate

\section{DISCUSSION}

Diagnosing and managing caesarean scar pregnancy is a clinical challenge. With rising section rates more cases are coming forward where pregnancy implants in the scar niche. This type of pregnancy has potential to grow into adherent placenta syndrome or end in massive haemorrhage during spontaneous or induced abortions. Either way life threatening bleeding is inevitable. The present study shows that timely identification and management is possible with good resolution of Scar pregnancies. The index of suspicion of a CSP in woman with previous history of CS should be high, since there no discernible symptoms in early pregnancy. In our experience $55 \%$ patient presented without complaints with just in first trimester for termination of pregnancy. Four women had presented with an attempted medical abortion and three cases with failed dilatation and evacuation with heavy bleeding per vaginum.

Diagnosis in such cases becomes difficult, because the anatomical site of pregnancy in the niche of the scar, increased vascularity and relation of gestational sac to the uterine cavity and cervix, which are diagnostic criteria for CSP are lost after an attempted D/E or medical abortion. We in the present study also found that most of the classical features of ultrasound diagnosis of CSP were absent in women with a history of prior medical abortion and surgical evacuation. In these cases, the uterine cavity was full of blood clots making in difficult to document USG signs. Two women showed definite rent in the scar with haematoma obliterating all signs.

We were able to diagnose classical signs of CSP by USG in only $70 \%$ of cases. Presently there are no recommendations for a routine ultrasound scan before first trimester termination of pregnancy even in the women with history of previous caesarean section. During this study we realized that an ultrasound scan before attempting termination of pregnancy in previously sectioned woman should be done, since many of them could very well be scar pregnancies and a planned termination with local/systemic methotrexate and or with Foley's balloon tamponade will save these women from torrential haemorrhage during medical or surgical abortions. Timely diagnosis and elective termination of scar pregnancies will also halt their progression to PAS if the pregnancy is continued. When these women decide to continue the pregnancy many of them become candidates for morbid placental adherences which has again an inherent risk of huge intra-operative blood loss, shock, need for massive transfusions and caesarean hysterectomy.

Cali et al in a unique retrospective analysis, studied the first trimester ultrasound scans of women with morbidly adherent placenta requiring caesarean hysterectomies found that the scan clearly showed a CSP in first trimester. ${ }^{12}$ USG diagnosis of the CSP rests upon findings of an empty uterine cavity, and gestation sac at the scar site with increased vascularity on Doppler evaluation. Ultrasound imaging in these cases allows an early diagnosis and safer management without complication and with preservation of uterus. ${ }^{8,13}$

Seow used a definite set of criteria for USG diagnosis of CSP lie an empty uterus with well delineated endometrium, an empty cervical canal, the G. sac with double ring sign in anterior isthmic portion pregnancy sac embedded in the fibrous tissue of the scar. ${ }^{8}$ Calli and colleagues devised an unique 'crossover sign' for US evaluation of CSP implantation site to determine the cases that would progress severe variants of MAP such as placenta accrete and percreta. Using a simple and reproducible method they ascertained the relationship between ectopic sac, anterior uterine wall and caesarean scar, by 'crossover sign' to predict MAP. ${ }^{12}$ In this study we were able to diagnose CSPs with ultrasound imaging and Doppler in $70 \%$ cases enabling us to offer them termination of pregnancies after counselling these women regarding the consequences of both termination and continuation of pregnancy. However, the definite diagnosis is not always possible in all cases and many will be missed due to pitfalls in diagnosis, especially after an attempted medical or surgical curettage or in women with spontaneous abortions since there are no typical findings. Correct interpretation of findings can lead to better management and avoidance of life-threatening consequences. ${ }^{14}$ The difficulty also arises in differentiating between and CSP and an inevitable abortion, though during last two decades ultrasound diagnosis has improved thanks to better machines and resolution. ${ }^{15}$

Like the diagnosis, management of CSP is also not less challenging. Due to risk of brisk haemorrhage medical or surgical evacuation is not advisable. Counselling these women especially is tricky since these cases have a 
potential for life threatening bleeding whether they opt to terminate or continue the pregnancy. After explaining the consequences of both, many women would agree for termination of pregnancy under controlled conditions and medical management with methotrexate (MTX). Systemic and/or local MTX injection again needed further counselling.

Timor-Tritsch et al reported a case of with prior one CS diagnosed as 'missed abortion' which in fact was a scar pregnancy) was referred with vaginal bleeding a repeat scan showed a scar hematoma. Foleys tamponade and during a repeat $\mathrm{D} / \mathrm{E}$ resulted in a blood loss of over 2000 $\mathrm{ml}$ and led to laparotomy with total hysterectomy to control the bleeding. ${ }^{16}$ In our series we had woman with similar presentation referred from outside with attempted curettage and profuse bleeding since the uterine cavity was full of blood no diagnosis could be made a repeat dilatation and evacuation resulted in massive bleeding requiring transfusion of six units of blood and four units of fresh frozen plasma. Foley's catheter tamponade was done to stop haemorrhage, patient required an intensive care unit (ICU) care for four days post-surgery.

Since a medical or surgical termination of scar pregnancy is risky many other modalities have been tried, like single dose systemic methotrexate in dose of $1 \mathrm{mg} / \mathrm{kg}$ body weight or $50 \mathrm{mg}$ intramuscular (IM) injections is tried as a first line treatment. ${ }^{15,16}$ Many researchers have multiple dose sequential methotrexate with intravenous and intramuscular route have been tried at the interval of two to three days. ${ }^{17}$ In this series we treated 21 women diagnosed with CSP with local MTX under USG guide and foleys balloon in utero, with successful resolution and no complication. Response to treatment was monitored by serial beta HCG level every 48 hours and catheter was removed after 48 hours. Three women in our experience needed a controlled dilatation and evacuation for failed MTX treatment (two women had plateau in beta HCG levels and one woman showed a rise). Eight of our patients had a successful treatment with systemic and five women received a local MTX injection. Except two patient none had serious complication, one woman was transferred to ICU for haemorrhagic shock-made a full recovery eventually, and in one woman a hysterectomy was done for intractable haemorrhage.

Other possible mode of treatment is surgical excision of the scar pregnancy either by hysteroscopy or laparoscopy and has been tried successfully. Kiyak reports a case of CSP managed with laparoscopic excision of scar and repair of esthmocele with barbed wire and found that this is safe and effective method with good recovery and no residual scar defect. ${ }^{18}$ Yang reported successful treatment of thirty-nine patients of CSP with hysteroscopic removal of products of conception, and found the method feasible and safe. Some of these patients received preoperative 25 $\mathrm{mg}$ oral mifepristone twice daily for three days and some received methotrexate. All women underwent bilateral preop uterine artery embolization. ${ }^{19}$ Elective laparotomy with either a local excision of CSP or hysterectomy is a viable and safe option with certain indications or sometimes an emergency hysterectomy may be needed for failure to control haemorrhage, during a medical of surgical treatment, we had such patient where total hysterectomy was needed. Uterine artery embolization as a primary and only intervention or along with other medical and surgical management has also been tried successfully with lesser complications. ${ }^{20}$ Yifeng et al in a retrospective cohort study of 58 women with scar pregnancy used preoperative uterine artery embolization before laparoscopic and hysteroscopic surgery and found it to be an effective treatment with shorter hospital stays. ${ }^{21}$ Trans-abdominal ultrasound guided intra sac injection of MTX is a safe and feasible approach. Placement of a Foley's balloon catheter inside uterus prevents any possible bleeding. This can be done in a single sitting with interventional radiology department without anaesthesia. There are fewer or no serious consequences. Doubilet and colleagues tried sonography guided minimal invasive treatment with potassium chloride injection in the gestation sac for 27 cases of unusual ectopic pregnancies including CSP and found this method and effective and safe alternative to systemic medications. ${ }^{22}$ Zhang and colleagues even tried trans vagina surgical excision of CSPs in 25 subjects and found it simple and feasible procedure with low complication rate and in our experience local injection of MTX transabdominally under USG guidance give best results and least complications. ${ }^{23}$ Timor-Trish also believes that intra-gestational sac injection is a simple and definitive treatment in CSP between 6-8weeks of pregnancy and should be considered first line approach in women desirous of future pregnancy. ${ }^{16}$ Of our patients benefitted by this intervention showed complete resolution as was observed by declining beta HCG titres. There were no complaints on follow up, only one woman had persistent bleeding, spotting for three weeks due to resolving scar hematoma. There is a significant evidence that CSP is a precursor of PAS (placenta accreta syndrome) and since not all CSP cases require hysterectomy and can be managed conservatively, without the loss of an organ, it seems logical that timely diagnosis and conservative approach to management of CSPs will serve to preserve uterus and fertility. ${ }^{24}$

\section{CONCLUSION}

Caesarean scar pregnancy is a diagnostic and management challenge in modern obstetrics. Early ultrasound diagnosis helps in planning a successful medical treatment, prevent life threatening haemorrhage and hysterectomy later. Ultrasound imaging may be unreliable in diagnosis of CSP in case of attempted medical or surgical abortion. Elective termination of CSP by intra-gestational sac methotrexate injections under Ultrasound guidance, is feasible, safe, acceptable and effective method with minimal side effects.

Funding: No funding sources Conflict of interest: None declared 
Ethical approval: The study was approved by the Institutional Ethics Committee

\section{REFERENCES}

1. Larsen JV, Solomon MH. Pregnancy in a uterine scar sacculus-an unusual cause of postabortal haemorrhage. A case report. S Afr Med J. 1978;53(4):142-3.

2. Fylstra DL: Ectopic pregnancy within a cesarean scar: A review. Obstet Gynecol Surv. 2002;57:537-54.

3. Ash A, Smith A, Maxwell D. Caesarean scar pregnancy. BJOG. 2007;114:253-63.

4. Pędraszewski P, Wlaźlak E, Panek W, Surkont G: Cesarean scar pregnancy - a new challenge for obstetricians. J Ultrason. 2018;18:56-62.

5. Miller DA, Chollet JA, Goodwin TM. Clinical risk factors for placenta previa-placenta accreta. Am J Obstet Gynecol. 1997;177:210-4.

6. Timor-Tritsch IE, Monteagudo A, Cali G, Vintzileos A, Viscarello R, Al-Khan A, Zamudio S, Mayberry P, Cordoba MM, Dar P. Cesarean scar pregnancy is a precursor of morbidly adherent placenta. Ultrasound Obstet Gynecol. 2014;44:346-53.

7. Zosmer N, Fuller J, Shaikh H, Johns J, Ross JA. Natural history of early first-trimester pregnancies implanted in Cesarean scars. Ultrasound Obstet Gynecol. 2015;46:367-75.

8. Seow KM, Huang LW, Lin YH, Lin MYS, Tsai AYL, Hwang JL. Cesarean scar pregnancy: issues in management. Ultrasound Obstet Gynecol. 2004;23:247-53.

9. Ouyang Y, Li X, Yi Y, Gong F, Lin G, Lu G. Firsttrimester diagnosis and management of cesarean scar pregnancies after in vitro fertilization-embryo transfer: a retrospective clinical analysis of 12 cases. Reprod Biol Endocrinol. 2015;13:126.

10. Jurkovic D, Hillaby K, Woelfer B, Lawrence A, Salim R, Elson CJ. First-trimester diagnosis and management of pregnancies implanted into the lower uterine segment Cesarean section scar. Ultrasound Obstet Gynecol. 2003;21:220-7.

11. Timor-Tritsch IE, Cali G, Monteagudo A, Khatib N, Berg RE, Forlani F, et al. Foley balloon catheter to prevent or manage bleeding during treatment for cervical and cesarean scar pregnancy. Ultrasound Obstet. 2015;46:118-23.

12. Cali G, Forlani F, Timor-Tritsch E, PalaciosJaraquemada J, Minneci G, Anntonio FD. Natural history of Cesarean scar pregnancy on prenatal ultrasound: the crossover sign. Ultrasound Obstet Gynecol. 2017;50:100-4.

13. Vial Y, Petignat P, Hohlfeld P. Pregnancy in a cesarean scar. Ultrasound Obstet Gynecol. 2000;16:592-3.
14. Selvaraj LR, Rose N, Ramachandran M. Pitfalls in ultrasound diagnosis of cesarean scar pregnancy. J Obstetr Gynecol India. 2018;68:164-72.

15. Peterson CB, Hoffmann E, Larsen CR, Nelson HS. Cesarean scar pregnancy: a systematic review of treatment Studies. Fertility and Sterility. 2016;104(5).

16. Timor-Tritsch IE, Monteagudo A, Agten AK. Cesarean scar pregnancy diagnosis and management. Obstetrics-Gynecol Women's Health. 2015. Available at: https://www.contemporaryobgyn.net/obstetricsgynecology-womens-health. Accessed on: 01 July 2020.

17. Kutuk MS, Uysal G, Dolanbay M, Ozgun MT. Successful medical treatment of cesarean scar ectopic pregnancies with systemic multidose methotrexate: single-center experience. J Obstet Gynaecol Res. 2014;40:1700-6.

18. Kiyak H, Wetherilt LS, Seckin KD, Polat I, Kadirogullari P, Laparoscopic Excision of a scar pregnancy and isthmocele repair. J Minim Invasive Gynecol. 2018;25(4):582.

19. Yang Q, Piao S, Wang G, Wang Y, Liu C. Hysteroscopic surgery of ectopic pregnancy in the cesarean section scar.J Minim Invasive Gynecol. 2009;16(4):432-6.

20. Wu X, Xue X, Wu X, Feng L, Wu X, Zhao A, et al. Combined laparoscopy and hysteroscopy vs. uterine curettage in the uterine artery embolization-based management of cesarean scar pregnancy: a cohort study. Int J Clin Exp Med. 2014;7:2793-803.

21. He Y, Wu X, Zhu Q, Wu X, Feng L, Wu X, et al. Combined laparoscopy and hysteroscopy vs. uterine curettage in the uterine artery embolization-based management of cesarean scar pregnancy: a retrospective cohort study. BMC Women's Health. 2014; $14 ; 116$.

22. Doubilet PM, Benson CB, Frates MC, Ginsburg E. Sonographically guided minimally invasive treatment of unusual ectopic pregnancies. J Ultrasound Med. 2004;23:359-70.

23. Zhang HH, Junrong Shi AEJ, Yang CY, Liang EY, Gao CX, et al. Transvaginal surgical management of cesarean scar pregnancy II (CSP-II): an analysis of 25 cases. Med Sci Monit. 2015;21:3320-6.

24. Jauniaux E, Chantraine F, Silver RM, Langhoff-Roo J. FIGO consensus guidelines on placenta accreta spectrum disorders: Epidemiology. Int J Gynecol Obstet. 2018;140:265-73.

Cite this article as: Choudhary A, Tanwar M, Nimonkar S, Singh S. The menace of caesarean scar pregnancy: a management challenge in modern obstetrics. Int J Reprod Contracept Obstet Gynecol 2020;9:4057-62. 